\title{
RELATION BETWEEN STRESSORS, COPING STRATEGIES AND SELF-EFFICACY AMONG PATIENTS UNDERGOING HEMODIALYSIS
}

\author{
Amal Bakr Abo El-Ata ${ }^{1}$; Reda Ebraheim Elmowafi ${ }^{2}$; Abeer Elsayed Berma ${ }^{3}$ : Nadia $^{2}$ \\ Mohamed Ibrahim Wahba ${ }^{4}$ \\ Assist. Prof. of Medical Surgical Nursing ${ }^{I}$; Assist. Prof. of Family \& Community Health \\ Nursing $^{2}$; Assist. Prof. of Psychiatric Nursing and Mental Health Department ${ }^{3}$; lecturer in \\ Psychiatric Nursing and Mental Health Department ${ }^{4}$, Faculty of Nursing-Port Said \\ University, Egypt
}

\begin{abstract}
Background: Hemodialysis is the most common method used to treat advanced and permanent kidney failure. Identifying stressors, self-efficacy and coping strategies used by patients undergoing hemodialysis may help nurses and health care providers to gain a clearer understanding of the condition of these patients and thus, institute effective care planning. Aim: Assess relation between stressors, coping strategies and self-efficacy among patients undergoing hemodialysis. Subjects and method: Design: A descriptive correlational research design was used. Subjects: This study implemented among 100 hemodialysis patients. Setting: The study was carried out in hemodialysis unit at El-Salam Hospital in Port-Said city, Egypt. Tools: Three tools were utilized to collect data for this study including; Hemodialysis Stressor Scale, Self-Efficacy for Managing Chronic Disease6-itemScale and Coping Strategies Scale. Results: Most prominent increase in percent score among all stressors associated with chronic hemodialysis treatment was related to social life. Patients were adaptive with stressors by the use of affective-oriented coping strategies more than problem-oriented coping strategies, nearly two thirds of the studied patients had low level of self-efficacy. Conclusion \&Recommendations: There were statistically significant negative correlations between total scores of coping strategies, self-efficacy and stressors among the studied patients. While, there was a statistically significant positive correlation between total scores of coping strategies and self-efficacy. So, Continuous educational programs should be held by health professionals for patients about proper coping methods, problem solving strategies and stress management techniques to alleviate stressors associated with chronic hemodialysis treatment and maintain compliance to treatment regimen. This will empower their self-efficacy.
\end{abstract}

Keywords: Coping Strategies, Hemodialysis, Self-Efficacy, Stressors, 


\section{INTRODUCTION}

Worldwide, hemodialysis is one of treatment modalities for patients with end stage renal diseases before transplantation, non-adherence to hemodialysis is the most common cause for morbidity and mortality(Khan \& Ahmad, 2020 ) .Stressors are importance among patients receiving dialysis, as these affect their psycho-social and physiological wellbeing. Thus, nephrologists, nurses and family members play an important role in providing patients with effective physiological and psycho-social support. The influence of the symptoms of end stage renal disease on patients' quality of life, and the frequency of periodic hemodialysis, the compliance of patients with treatment regimen and the negative side effects of the disease on patients are the strongest stressors. Physiological and psychosocial stressors have not been weighed against each other in this study, yet compared to other studies the psychosocial stressors seem to be particularly difficult to cope with (Tchape, Tchapoga, Atuhaire, Priebe \& Cumber, 2018).

Stress is complex and is a state showed by a specific syndrome, consisting of unspecific changes produced in a biological system. It can be divided into three phases; alarm (recognizing the stressor), adaptation (repair of the physical damage caused by the stressor), and exhaustion (overload, if maintained in the stressful situation) (Fink, 2016). Stress has been approached in psychology, emphasizing the stressors, which are situations that require adaptation, and originate out of the human like a demand of something or someone, internal like self-expectations or yet, situations that irritate, scare, excite, confuse, or even those that cause extreme happiness (Tennant, Langeluddecke \& Byrne, 2009).

The long term hemodialysis patients are subjected to frequent, recurring stressful situations. In addition, they must tolerate the usual continuous stress of chronic illness and treatment regimen. There is a constant uncertainty about their life expectancy, as well as about immediate medical complications. Hemodialysis patients faced with significant changes in life style, occupation, family responsibilities and financial status. Changes in lifestyle, physical energy, and personal appearance. The stressors are dealt with according to the meaning that they have to those involved, and the health of the people with a chronic disease depends on the result from that coping process (Tchape et al., 2018).

An important reason for studying coping is that it's hypothesized role as a mediator of the effects of stress on mental and physical health. The relationship between coping and 
psychological outcomes is considerable. Stress and coping research is like the stress process. It is dynamic, multidimensional, complex, and fascinating (Folkman, 2012). Coping is defined as the way one adapt to stressors psychologically, physically and behaviorally. It is the ability one develops to deal with problems and stress (Linda \& Robynn, 2014)).

The coping process has two important functions, regulate one's emotional responses to the stressful situations, which is emotion-focused coping; and reduce the demands of the stressful situation or expand the resources to deal with it, which is problem-focused coping (Folkman \& Lazarus, 1988) Effective coping refers to the effectiveness of the coping patterns affirming that is a threat is resolved, the coping strategy will be used again in similar situations. If the threatening situation is not effectively managed, the ineffective coping can result in a crisis causing a physiological and psychological imbalance (Lazarus \& Folkman,. 1984).

Self-efficacy is one of the most enabling positive psychological models. It is the optimistic self- belief in person's competence of successfully accomplishing a task and producing a favorable outcome (Schunk \& Usher, 2011). It is a term denoting the person's confidence in his own capability to cope with a specific situation. Self-efficacy has two different components; outcome expectancy, which means the belief in a certain behavior being supportive in a specific situation; and efficacy expectancy, which is the belief in one's capability to accomplish such behavior (Salomonsson, Gullberg, Alehagen \& Wijma, 2013). Self-efficacy determines how much effort persons put into dealing with challenges, as well as their resilience in the face of adversity. Furthermore, it affects amount of stress and anxiety while individuals facing stressful situations (Dormann, Fay, Zapf \& Frese, 2006).

General self-efficacy may have noteworthy effects on the behaviors or activities. Patients with chronic illness who had a strong sense of self-efficacy view challenging problems and illness as tasks to be mastered, develop interest in the activities in which they participate and recover quickly from setbacks and disappointments, while people with a weak sense of self efficacy avoid challenging tasks, believe that difficult tasks and stressors are beyond their abilities and focus on negative outcomes (Cherry, 2018).

Psychological factors crucially influence successful rehabilitation in many patients with chronic illness. Some factors often thought to be conducive to successful rehabilitation in any chronic illness include a stable nurse-patient relationship, a meaningful goal in life 
for the patient, and the meaning of the symptom or disability to the patient (Neirynck, Glorieux, Schepers, Verbeke \& Vanholder, 2015).

Stress is common in patients with hemodialysis and negatively affects health-related quality of life and other health-related outcomes. Long term hemodialysis patients need someone to turn to in times of stress to prevent despair and depression. It is imperative that clinicians recognize the value of early screening for stress and initiate preventive and treatment measures. Nurses play an important role in helping patients' undergone hemodialysis to cope with stressors, ascertain the effectiveness of current coping skills and improve their self-efficacy (Puzantian, Puzantian \& Hannan, 2017).

\section{Significance of the study:}

Stressors are anything that poses a challenge or a threat to human well-being. Dialysis patients need to deal and cope with various aspects of their disease. Identifying the level of self-efficacy and coping strategies provides valuable information for planning specific treatment and improving the performance of health care team. The role of the nurse is to contribute to the preventive and therapeutic intervention to help patients to adapt to treatment regimen and eliminate their stress, fear and anxiety. So, nurses should help patients to understand the effects of excessive stress and how to overcome the impacts of hemodialysis as regard physiological and psychological problems.

\section{AIM OF STUDY:}

The aim of this study was to assess the relation between stressors, coping strategies and self-efficacy among patients undergoing hemodialysis in El-Salam hospital.

\section{Research Objectives:}

1. Identify stressors among patients undergoing hemodialysis.

2. Determine coping strategies that used by patients undergoing hemodialysis.

3. Measure self-efficacy of patients undergoing hemodialysis.

\section{SUBJECTS AND METHOD:}

\section{Research design:}

A descriptive research design was followed in this study. 


\section{Study setting:}

The study was conducted in hemodialysis unit at El-Salam hospital in Port Said city, Egypt.

\section{Subjects:}

The study subjects comprised a convenient sample of 100 hemodialysis patients.

\section{Tools of data collection:-}

Three tools were utilized to collect the necessary data for this study. They were: Hemodialysis Stressor Scale, General Self-Efficacy Scale (GSE) and Coping Strategies Scale.

\section{First tool: Hemodialysis Stressor Scale:}

This scale was developed by Bladree \& Powers (1982), in an English language, and translated into Arabic language by El-Matty, Rashwan, Abd El-Hamid \& Abd El-Halim (2000), it is used to measure psychosocial and physiological stressors as perceived by hemodialysis patients. It is consisting of 28 items distributed as the following; stressors related to social life (6 items), stressors related to change in work condition (3 items), stressors related to change in body image ( 2 items), stressors related to eating and drinking limitations (2 items), stressors related to nature of illness (9 items), and finally stressors related to presence of physiological symptoms (6 items).

\section{Scoring system:}

This scale was rated using a 3-point Likert response format, ranging from (0) "Not perceived as a stressor" to (2) "Severely perceived as a stressor".

Second tool: Self-Efficacy for Managing Chronic Disease6-itemScale (Lorig, Sobel, Ritter, Laurent, , Hobbs)

It is developed by Lorig, Sobel, Ritter, Laurent \& Hobbs., (2001), in an English language, and translated to Arabic language by researcher to suit the patients' language. This scale is a self-report measure of self-efficacy; it is used to measure self-efficacy of patients. It consists of 6 items scale from 1 (not at all confident) to 10 (totally confident)

\section{Scoring system:}

The score for each item is the number circled. If two consecutive numbers are circled, code the lower number (less self-efficacy). If the numbers are not consecutive, do not score the item. The score for the two scale is the mean of the six items. If more than two items are missing, do not score the scale. Higher number indicates higher self-efficacy. 


\section{Third tool: Coping Strategies Scale.}

This scale was developed by Jalowieic \& Powers (1981), in an English language, and translated into Arabic language by El-Matty et al. (2000), to assess thoughts and actions that individuals use to cope with stressful encounters of everyday living. It consists of two parts, depicting two coping patterns including problem-oriented and affectiveoriented. Problem-oriented coping strategies aimed at solving problems or handling stressful situations, they are divided into nine coping strategies related to active role, and five coping strategies related to passive role. Affective-oriented coping strategies are emotion focused strategies used to manage emotion accompanying stressful situations including coping strategies related to withdrawal (6 items), neurotic reaction (4 items), dream and fantasy (3 items), projection ( 5 items), and resign the self to the fate ( 5 items). Respondents rated each statement of the scale using a three-point Likert scale ranging from 0 (Disagree), 1 (Uncertain) to 2 (Agree).

In addition to personal and clinical data sheet: Structured sheet was developed by the researchers in an Arabic language. The sheet elicits personal characteristics as age, sex, marital status, educational level, and working status. It also included questions that cover data related to history of dialysis and frequency of dialys is per week.

\section{Tool 1 :}

\section{Reliability:}

Internal consistency for the BAI $=($ Cronbach's $\mathrm{a}=0.92)$ Test-retest reliability $(1$ week $)$ for the BAI $=0.75$ (Beck, Epstein, Brown, \& Steer, 1988)

\section{Validity:}

The BAI was moderately correlated with the revised Hamilton Anxiety Rating Scale (.51), and mildly correlated with the Hamilton Depression Rating Scale (0.92).

\section{Tool 2:}

\section{Reliability:}

Internal reliability for Self-Efficacy for Managing Chronic Disease6-itemScale = Cronbach's alphas between .76 and .90

\section{Validity:}

Self-Efficacy for Managing Chronic Disease6-item Scale is correlated to emotion, optimism, and work satisfaction. Negative coefficients were found for depression, stress, health complaints, burnout, and anxiety. 


\section{Pilot Study:}

A pilot study was carried out of the study subjects which included ten patients $(10 \%)$, who were selected randomly. It was done to ascertain the relevance, clarity and applicability of the used tools and to estimate the time needed to fill in the data collection instruments. It also helped to find out any obstacles and problems that might interfere with data collection. According to the pilot study, no modifications were done. It was simple and clear. The pilot study was conducted at the time from the first to the mid of December 2018.

\section{Field work:}

The researchers attended the hospital director to introduce self, explain the aim of the study and obtain an official permission, then; director referred the researchers to the responsible matron of the hospital. After explanation of purpose of the study, patients' oral consents were taken. The researchers interviewed those who gave their consent. The data collection process was conducted using face to face interview technique that was done on an individual basis to ensure privacy and confidentiality of the collected data. Each interview lasted from 35 to 45 minutes, depending on the response of the interviewee. The data was collected through 3 days per week. The collection of data covered a period of four months from 20 th December 2018 to $20^{\text {th }}$ April 2019. After completion, the researchers ensured that all statements included in the instruments were completed. Then, the studied patients were thanked for their cooperation.

\section{Administrative design:}

Before starting any step in the study, an official letter was issued from Dean of the Faculty of Nursing, Port Said University to the director of the above mentioned setting requesting his cooperation and permission to conduct the study, after explaining the aim of the study.

\section{Ethical Considerations:}

The research proposal was approved by the Scientific Research Ethics Committee of the Faculty of Nursing, Port Said University. A verbal consent was obtained from each patient to participate in the study after explaining the purpose of the study. The studied patients were informed that their participation is voluntary and they have the right to withdraw from the research at any time. Also, they were ensured that the information 
would remain confidential and used for the research purpose only, and the anonymity was guaranteed. Ethics, values, culture and beliefs were respected.

\section{Statistical design:}

Data were fed to the computer and analyzed using (SPSS) software package version 23.0. Qualitative data were presented using descriptive statistics in the form of numbers and percentages. Quantitative data were described using means and standard deviations. Comparison between different groups regarding categorical variables was tested using Chisquare test. Significance of the obtained results was judged at $\mathrm{P}$-value $\leq 0.05$.

\section{RESULTS}

Table (1): illustrates the personal characteristics of the studied patients. The results revealed that patients' mean age of $55.45 \pm 11.4$ years. It is also observed that more than half of the studied patients (59\%) were males. The majority of the studied patients $(80 \%)$ were married and $71 \%$ of them were not working. Regarding the beginning of dialysis $37 \%$ of the studied patients began dialysis from more than four years, and $81 \%$ undergone hemodialysis three times per week.

Table (2): clarifies that the most prominent increase in percent score among all stressors associated with chronic hemodialysis treatment among the studied patients was related to social life stressors which reached $47.3 \%$, followed by stressors related to presence of physiological symptoms and change in body image which constituted $46.2 \%$ and $44 \%$ respectively. It was clear from the table that, $44 \%$ of the studied patients severely perceived nature of illness, presence of physiological symptoms, change in work condition, change in body image, eating and drinking limitations, and social life as stressors associated with chronic hemodialysis treatment.

Figure (1): describes affective-oriented coping strategies used by the studied hemodialysis patients. The figure represents that more than half $(53.6 \%)$ of the studied patients resign the self to the fate to deal with stressors associated with chronic hemodialysis treatment, while projection used by only $26 \%$ of the studied patients.

Table (3): shows percent scores of problem-oriented coping strategies used by the studied hemodialysis patients. As revealed from the table that, hemodialysis patients depended on active role coping strategies (67.7\%) noticeably more than passive role 
coping strategies $(48.2 \%)$ in dealing with stressors associated with chronic hemodialysis treatment.

Table (4): indicates the percent scores of affective-oriented and problem-oriented coping strategies used by the studied hemodialysis patients. It was obvious that, more than half $(58 \%)$ of hemodialysis patients were adaptive with stressors associated with chronic hemodialysis treatment by the use of affective-oriented coping strategies. While, 37.2\% used problem-oriented coping strategies.

Figure (2): It was clear from the figure that nearly two thirds of the studied patients $(67 \%)$ had low level of self-efficacy, while $33 \%$ of them had high level.

Table (5): it was evidenced that there were statistically significant negative correlations between total scores of coping strategies, self-efficacy and stressors among the studied patients undergone hemodialysis where $(\mathrm{r}=-0.197,-0.191$ respectively). While, there was a statistically significant positive correlation between total scores of coping strategies and self-efficacy among studied patients as $(r=r=0.216)$. 
Table (1): Distribution of the studied patients according to their personal and clinical characteristics $(\mathrm{n}=100)$

\begin{tabular}{|c|c|c|}
\hline \multirow[t]{2}{*}{ Personal and clinical characteristics } & \multicolumn{2}{|c|}{ Studied patients } \\
\hline & No & $\%$ \\
\hline \multicolumn{3}{|l|}{ Age ( years) } \\
\hline$<30$ & 5 & 5 \\
\hline $30<40$ & 7 & 7 \\
\hline $40<50$ & 27 & 27 \\
\hline $50<60$ & 26 & 26 \\
\hline$\geq 60$ & 35 & 35 \\
\hline Mean \pm SD & \multicolumn{2}{|c|}{$55.45 \pm 11.4$} \\
\hline \multicolumn{3}{|l|}{ Sex } \\
\hline Male & 59 & 59 \\
\hline Female & 41 & 41 \\
\hline \multicolumn{3}{|l|}{ Marital Status } \\
\hline Single & 3 & 3 \\
\hline Married & 80 & 80 \\
\hline Divorced & 2 & 2 \\
\hline Widowed & 15 & 15 \\
\hline \multicolumn{3}{|l|}{ Family no. } \\
\hline$\leq 3$ & 22 & 22 \\
\hline $4-5$ & 59 & 59 \\
\hline$>5$ & 19 & 19 \\
\hline \multicolumn{3}{|l|}{ Educational Level } \\
\hline Illiterate & 26 & 26 \\
\hline Read and write & 10 & 10 \\
\hline Primary education & 22 & 22 \\
\hline Secondary education & 19 & 19 \\
\hline Higher education & 23 & 23 \\
\hline \multicolumn{3}{|l|}{ Working Status } \\
\hline Working & 29 & 29 \\
\hline Not working & 71 & 71 \\
\hline \multicolumn{3}{|l|}{ Start of Dialysis ( years) } \\
\hline$<2$ & 30 & 30 \\
\hline $2-4$ & 33 & 33 \\
\hline$>4$ & 37 & 37 \\
\hline \multicolumn{3}{|l|}{ Frequency of Dialysis (week) } \\
\hline Twice & 19 & 19 \\
\hline 3 times & 81 & 81 \\
\hline
\end{tabular}


Table (2): Percent scores of stressors associated with chronic hemodialysis treatment among the studied patients $(n=100)$

\begin{tabular}{|l|c|c|c|}
\hline \multirow{2}{*}{ Stressors } & \multicolumn{3}{|c|}{ Studied patients } \\
\cline { 2 - 4 } & $\begin{array}{r}\text { Not perceived } \\
\text { as a stressor }\end{array}$ & $\begin{array}{c}\text { Occasionally } \\
\text { perceived as a } \\
\text { stressor }\end{array}$ & $\begin{array}{r}\text { Severely } \\
\text { perceived as } \\
\text { a stressor }\end{array}$ \\
\hline Nature of Illness & 23.4 & 34.8 & 42.8 \\
\hline Physiological Symptoms & 9.2 & 44.6 & 46.2 \\
\hline Change in Work Condition & 27.3 & 31 & 41.7 \\
\hline Chang in Body Image & 18 & 38 & 44 \\
\hline Eating and Drinking Limitations & 15.5 & 42 & 42.5 \\
\hline Social Life Total & 20.2 & 32.5 & 47.3 \\
\hline & 18.9 & 37.1 & 44.0 \\
\hline
\end{tabular}

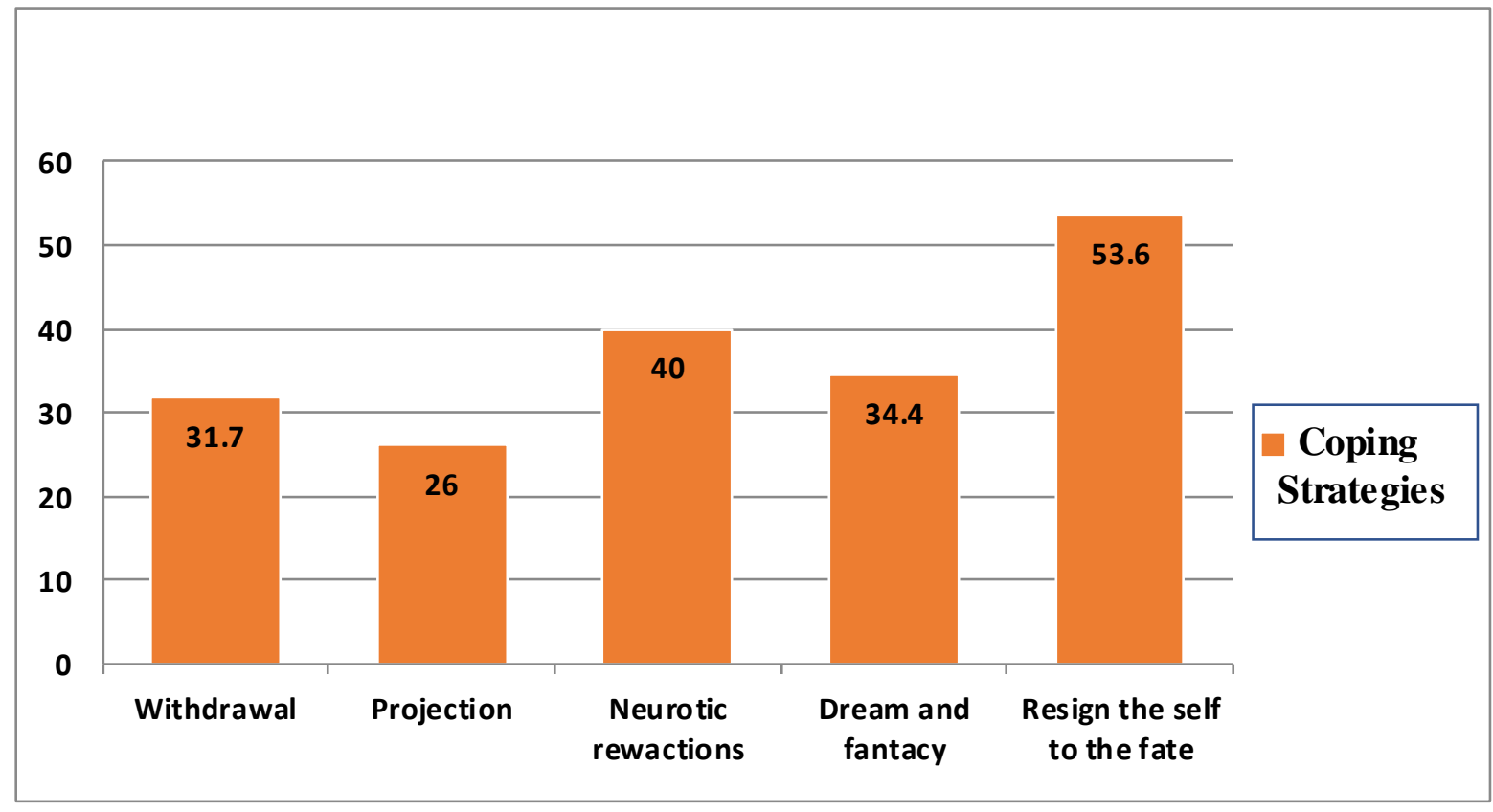

Figure (1) Distribution of affective-oriented coping strategies among the studied patients $(n=100)$ 
Table (3): Percent scores of problem-oriented coping strategies among the studied patients $(n=100)$.

\begin{tabular}{|l|c|c|c|}
\hline \multirow{2}{*}{$\begin{array}{l}\text { Problem-Oriented } \\
\text { Coping Strategies }\end{array}$} & \multicolumn{3}{|c|}{ Studied Patients Responses } \\
\cline { 2 - 4 } & Not agree & Not sure & Agree \\
\hline Active & 8.2 & 24.1 & 67.7 \\
\hline Passive & 24.4 & 27.4 & 48.2 \\
\hline
\end{tabular}

Table (4): Percent scores of affective-oriented and problem-oriented coping strategies among the studied patients $(\mathrm{n}=100)$

\begin{tabular}{|l|c|c|c|}
\hline \multirow{2}{*}{ Coping Strategies } & \multicolumn{3}{|c|}{ Studied Patients Responses } \\
\cline { 2 - 4 } & Not agree & Not sure & Agree \\
\hline Affective-oriented & 37.5 & 25.3 & 37.2 \\
\hline Problem-oriented & 16.3 & 25.7 & 58 \\
\hline
\end{tabular}

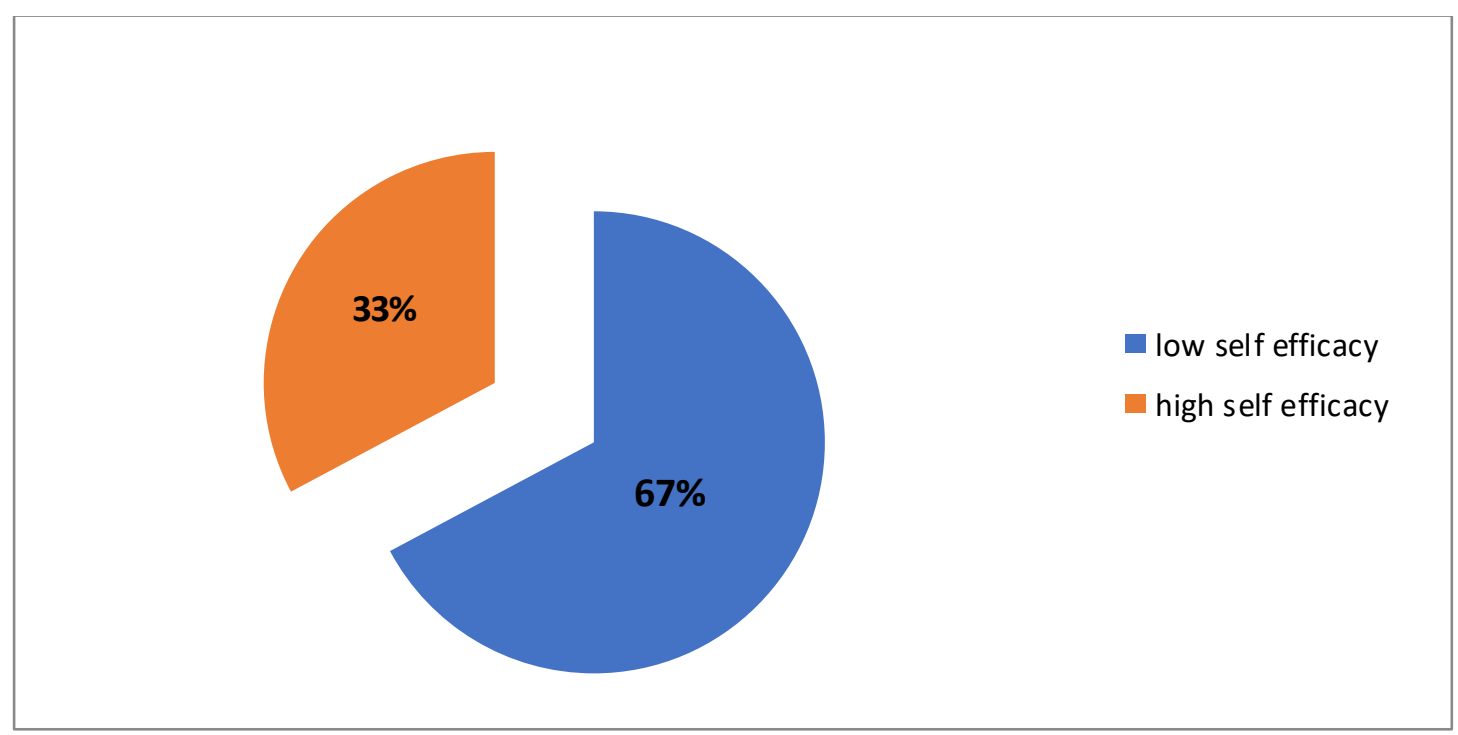

Figure (2): Distribution of self-efficacy levels among the studied patients $(n=100)$ 
Table (5): Correlation matrix between total scores of stressors, coping strategies and selfefficacy among the studied patients $(\mathrm{n}=100)$.

\begin{tabular}{|c|c|c|c|c|c|c|}
\hline \multirow{2}{*}{ Total Scores of } & \multicolumn{2}{|c|}{ Stressors } & \multicolumn{2}{|c|}{ Coping Strategies } & \multicolumn{2}{|c|}{ Self-Efficacy } \\
\hline & $\mathbf{r}$ & P- value & $\mathbf{r}$ & p-value & $\mathbf{r}$ & p-value \\
\hline Stressors & & & & & $r=-0.191$ & $\begin{array}{c}\mathrm{p}= \\
0.029 *\end{array}$ \\
\hline $\begin{array}{r}\text { Coping } \\
\text { Strategies }\end{array}$ & $\begin{array}{r}r=- \\
0.197\end{array}$ & $\begin{array}{r}p= \\
0.025^{*}\end{array}$ & & & & \\
\hline Self-Efficacy & & & $\begin{array}{r}r= \\
0.216\end{array}$ & $\begin{array}{r}p= \\
0.015^{*}\end{array}$ & & \\
\hline
\end{tabular}

$\mathbf{r}=$ Spearman's rho

*significant at $\mathbf{P} \leq \mathbf{0 . 0 5}$

\section{Discussion}

The problem of renal failure is increasing rapidly, chromic hemodialysis places severe stress on the psychosocial resources of the patient. Among the several causes of stress, there are numerous resources most pertinent to the patient. Stress arising from the demands of the dialysis regimen as adherence to medication instructions, diet and fluid restriction and attendance at time. Also, stress arising from the secondary psychosocial consequences of kidney failure and dialysis such as marital/sexual problems, loss of employment, change in body image, impaired bodily functions and financial stringencies. Hemodialysis patients are in urgent need to adhere to therapeutic regimen for the rest of their lives. Therefore, 
treatment regimens for patients undergoing hemodialysis should include broad coping strategies for dealing with psychosocial and physiological stressors to enhance their selfefficacy and attain better quality of life.

The present study revealed that, the most prominent increase in percent score among all stressors associated with chronic hemodialysis treatment was related to social life stressors. Social stressors including financial problems, changes in family responsibility, reversal in family role with spouse, decrease participation in social and leisure activities, and reversal in family role with children. This may be related to the nature of the illness, a matter which prevents the patient from achieving his social role and thus, necessitates one of the family member to play his/her role. Also, during this time, the patient and all family members focus their attention on the patient's health status rather than social life. So, most of the hemodialysis patients required not only help in the hospital setting but also expert care from vocational counselors, social workers, physical and occupational therapists, psychologists and professionally monitored support groups.

Accordingly, Ahmad and Al Nazly (2015), stated that mean score of psychosocial stressors was higher than the mean score of physiological stressors among patients undergone hemodialysis. So, attention should be focused towards the psychosocial stressors and also helping patients to utilize the coping strategies that help to alleviate the stressors. Also, an Egyptian study by El-Matty et al. (2000), pointed out that, social interactions of hemodialysis patients altered as a result of the disease.

One of the main objectives of the present study was to identify coping strategies among the studied patients undergoing hemodialysis. The results revealed that hemodialysis patients were adaptive with stressors associated with chronic hemodialysis treatment by the use of affective-oriented coping strategies more than problem-oriented coping strategies. This may be explained by that, the persons used more problem-focused coping if they had some control over health related situations, but they used more emotionfocused coping if they felt little or no control. So, health care team especially nurses should encourage dialysis patients to control many aspects of their disease and treatment regimen as possible, in order to promote the greater use of problem oriented coping strategies which can lead to more successful adaptation to the stressors encountered during disease.

The importance of this result has been demonstrated by Silva et al, 2016 who illustrated that, the way to handle the difficulties inherent to the disease was revealed by coping strategies that were based on emotion as on the issue. Thus, efforts have been made 
to administer or change the initial problems, as well as attempts to replace or regulate the emotional impact of the disease. Similar results were identified by Dehkordi and Shahgholian (2013), in their study in Iran, the authors recommended that, as the most of the hemodialysis patients used emotion focused coping styles, it is suggested to consider educational programs on application of problem focused coping styles for these patients in order to decrease the pressures of the disease and treatment, and to promote their mental health, quality of life and efficiency.

Additionally, a study carried out in Turkey which studied coping strategies and stressors in patients with hemodialysis by Yeh and Chou (2007), shown that, the most commonly used coping strategies among patients were emotion-oriented, avoidance, and isolated thoughts, and the choice of coping strategy depended on the type of stressors. Similarly, Parvan et al. (2015), who studied coping methods to stress among patients on hemodialysis and peritoneal dialysis added that, the majority of patients in their study used emotion-oriented coping strategies to deal with the stress factors. Although many of the emotion-oriented coping strategies were identified as helpful coping strategies by the patients, because the problem-oriented coping strategies are more difficult to respond, these methods were not adequately applied, which could be due to lack of knowledge among the patients.

The results of the current study accentuated that, the most used affective-oriented coping strategies by the studied hemodialysis patients was resign the self to the fate to deal with stressors associated with chronic hemodialysis treatment. This is explained by the fact that, Arabian and Muslim countries cope with traumatic life episodes by using praying, meditation or doing other religious activities. Religious beliefs may provide patients chance for accepting sufferings and make pain easier to cope with. The result indicated that hemodialysis patients used religion as an avenue for dealing with anxiety surrounding death and imminent death. This finding was in agreement with a study conducted by Patel, Shah, Peterson \& Kimmel (2002), who reported that religious beliefs served as a positive coping tools for patients undergoing hemodialysis managing the burdens of their illness as well as improved social support and quality of life.

Understanding the function and theory of self-efficacy is important in developing simple and targeted implementations and supporting the efforts of chronic kidney disease patients to manage their illness (Sorait, 2018). The present results was also aimed to evaluate self-efficacy of patients undergoing hemodialysis. The findings of the present 
study explored that, nearly two thirds of the studied patients had low level of self-efficacy, while the rest of them had high level. This may be due to that end stage renal disease is considered a serious chronic disease impacting many aspects of patients' life, imposes many physical and mental stresses as well, and the patients didn't have appropriate and enough knowledge in relation to suitable approaches to cope with the burdens of their illness leading to lack of self-confidence and consequently, lowering their self-efficacy.

On the same line, an Egyptian study explored that, less than half of the studied patients undergoing hemodialysis had moderate level of self.-efficacy (Elsayed, 2018). The author recommended that there is a need for greater attention to teaching programs to improve patients' knowledge and self-care practices and self-efficacy to improve their health status and prevention of complications. Similar results were recognized by Royani, Rayyani, Vatanparast, Mahdavifar and Goleij (2015), in their study in Gorgan. The authors found that, it is necessary to pay attention to coping strategies, self-efficacy and self-care behaviors' education in order to empowering hemodialysis patients.

One of the conspicuous results of the present study, that there were statistically significant negative correlations between total scores of coping strategies, self-efficacy and stressors among the studied patients undergone hemodialysis. This negative correlation may be clarified by the point that, when the person has an appropriate knowledge, suitable coping methods, strong confidence in his abilities to achieve a task and efficacious behavior to grasp specific outcomes, all of these will lead to a reduction of anxiety and stress. In this respect, El-Matty et al. (2000), detected a statistically significant positive correlation between total scores of coping and stress for patients undergoing hemodialysis.

The results of the current study illustrated that there was a statistically significant positive correlation between total scores of coping strategies and self-efficacy among studied patients. Thus, health care team of patients undergoing hemodialysis should include a psychiatrist, a psychiatric nurse and a social worker to teach patients applicable coping strategies to control stress and maintain coping with the therapeutic regimen, subsequently, this will help in improving patient's self-efficacy.

\section{CONCLUSION:}

Based on the findings of the current study, it can be concluded that, the most prominent increase in percent score among all stressors associated with chronic hemodialysis treatment was related to social life stressors. Hemodialysis patients were adaptive with stressors associated with chronic hemodialysis treatment by the use of 
affective-oriented coping strategies more than problem-oriented coping strategies. Additionally, there were statistically significant negative correlations between total scores of coping strategies, self-efficacy and stressors among the studied patients. While, there was a statistically significant positive correlation between total scores of coping strategies and self-efficacy. Clearly, hemodialysis is one of the most disruptive and disturbing events for person to experience. Virtually, any patient undergoing chronic hemodialysis treatment will show stress and low self-efficacy.

\section{RECOMMENDATIONS:}

Based on the findings of the present study, the subsequent recommendations were proposed:

1- Designing and implementing an educational training program for nurses to increase their awareness of hemodialysis patients' stressors and appropriate coping strategies, emphasizing on the importance of holistic care and viewing patients as a whole bio psychosocial being.

2- Continuous educational programs should be held for patients about proper coping methods, problem solving strategies and stress management techniques to alleviate stressors associated with chronic hemodialysis treatment and maintain compliance to treatment regimen. This will empower their self-efficacy. These programs should be led by health professionals, especially psychiatric nurses.

3- Providing comprehensive updated booklet to hemodialysis patients about their illness to improve their awareness and self-efficacy.

4- Replication of this study is recommended using a wider probability sample and different settings.

5- Future studies are needed to assess the effectiveness of educational programs for patients undergoing hemodialysis on patients' stress and self-efficacy.

\section{REFERENCES}

Ahmad, M., Al Nazly, E. (2015). Hemodialysis: Stressors and coping strategies. Saudi J Kidney Dis Transpl 20 (4), 477-487.

Bladree, K., \& Powers, M. (1982). Stress identification and coping patterns in patients on hemodialysis. Journal of Nursing Research, 31, 107-112.

Cherry, A. (2018). Self-efficacy: Why believing in yourself matters. Very Will Mind Journal, 265 (3), 720-725.

Dehkordi, L., \& Shahgholian, N. (2013). An investigation of coping styles of hemodialysis patients. Iran Journal of Nursing Midwifery Research, 18 (1), 42-46. 
Dormann, C., Fay, D., Zapf, D., \& Frese, M. (2006). A state trait analysis of top satisfaction on the effect of core self-evaluation. Applied Psychology: An international review, 55 (1), 27-81.

E-Sayed, S. (2018). Assessment of self-care behaviors, self-efficacy and level of physical activity of patients undergoing hemodialysis; retrieved from DOI: 10.21608/pssjn.2018.33186.

El-Matty, G., Rashwan, H., Abd El-Hamid, M., \& Abd El-Halim, Z. (2000). Design, implementation and evaluation of health education program dealing with the psychological and physiological stressors, coping mechanisms and quality of life of chronic renal failure patients on hemodialysis. Unpublished Dissertation. Faculty of Nursing, Suez Canal University, Egypt.

Fink, G. (2016). Stress: Concepts Definition, History. Reference Module in neuroscience and Bio behavioral Psychology. Florey Institute of Neuroscience and Mental Health, University of Melbourne, Melbourne, VIC, Australia

Folkman, S. (2012). Stress, health, and coping: Synthesis, commentary, and future directions. The Oxford Handbook of Stress, Health, and Coping, Psychology, Health Psychology, Social Psychology; retrieved from 10.1093/oxford $\mathrm{hb} / 9780195375343.013 .0022$.

Folkman, S., \& Lazarus, R. (1988). Coping as a mediator of emotion. Journal of Personal and Social Psychology, 54, 466-475.

Jalowieic, A., \& Powers, M. (1981). Stress and coping in hypertensive and emergency room patients. Journal of Nursing Research, 30, 10-15.

Khan, S., \& Ahmad, I. (2020). Impact of hemodialysis on the wellbeing of chronic kidney diseases patients: a pre-post analysis. Middle East Current Psychiatry, 27(1), 1-5

Lazarus, R., \& Folkman, S. (1984). Stress, appraisal, and coping. New York: Springer publishing Company.

Linda, M., \& Robynn, F. (2014). Neeb's Fundamentals of Mental Health Nursing, ( $4^{\text {th }}$ ed.). F.A. Davis Company, Philadelphia.

Lorig KR, Sobel, DS, Ritter PL, Laurent, D, Hobbs, M (2001). Effect of a selfmanagement program for patients with chronic disease. Effective Clinical Practice, 4, pp. 256-262.

Neirynck, N., Glorieux, G., Schepers, E., Verbeke, F., \& Vanholder, R. (2015). Soluble tumor necrosis factor receptor 1 and 2 predict outcomes in advanced chronic kidney disease: A prospective cohort study; retrieved from PLOS ONE, 10, e0122073. 
Parvan, K., Ahangar, R., Hosseini, F., Abdollahzadeh, F., Ghojazadeh, M., \& Jasemi, M. (2015). Coping methods to stress among patients on hemodialysis and peritoneal dialysis. Saudi Journal of Kidney Disease Transplantation, 26 (2), 255-262.

Patel, S., Shah, S., Peterson, A., \& Kimmel, L. (2002). Psychosocial variables, quality of life, and religious beliefs in ESRD patients treated with hemodialysis. American Journal of Kidney Diseases, 40 (5), 1013-1022.

Royani, Z., Rayyani, I., Vatanparast, M., Mahdavifar, M., \& Goleij, J. (2015). The relationship between self-care and self-efficacy with empowerment in patients undergoing hemodialysis. Military Caring Sciences, 1 (2),

Salomonsson, B., Gullberg, M., Alehagen, S., \& Wijma, K. (2013). Self-efficacy beliefs and fear of childbirth in nulliparous women. Journal of Psychosomatic Obstetrics, 34 (3), 116-121.

Schunk, D., \& Usher, E (2011). Assessing self-efficacy for self-regulated learning. Handbook of self-regulation of learning and performance, 282-297.

Silva, R., Neto, V., Oliveira, G., Silva, B., Rocha, C., \& Holanda, J. (2016). Coping strategies used by chronic renal failure patients on hemodialysis. Escola Anna Nery Esc, 20, 111-118.

Sorait, W. (2018). The association of self-efficacy and self-management behavior in adult patients with chronic kidney disease: An integrative review. Journal of Kidney Treatment and Diagnosis, 1(1), 33-40.

Tchape, O., Tchapoga, Y., Atuhaire, C., Priebe, G., \& Cumber, S. (2018). Physiological and psychosocial stressors among hemodialysis patients in the Buea Regional Hospital, Cameroon Article: 30: 49. Tennant, C., Langeluddecke, p \& Byrne, D. (2009). The Concept of Stress; retrieved from 176:404-10.10.2020/j.schres.2016.05.024.

Yeh, S., \& Chou, H. (2007). Coping strategies and stressors in patients with hemodialysis. Psychosomatic Medicine, 69 (2), 182-190. 
العلاقة بين الضغوط النفسية ، استراتيجيات التكيف و الكفاعة الذاتيه لاي المرضى الذين يخضعون لغسيل الكلي

امل بكر ابو العطارضا ابراهيم الموافى، عبير السيد برمه، ناديه محمد

غسيل الكلى هو الطريقة الأكثر شيوعًا المستخدة لعلاج الفشل الكلوي المزمن. قد يساعد تحديد الضغوط النفسية ، و الكفاعة الذاتية ، واستراتيجيات التكيف التي يستخدمها المرضى الذين يخضعون لغسيل الكلى ، الممرضيبين ومقدمي الرعاية الصحية على اكتساب فهم أوضح لحالة هؤ لاء المرضى ، وبالتالي ، وضع تخطيط فعال للرعاية. الهدف: تقييم العلاقة بين الضغوط النفسيه واستراتيجيات التكيف و الكفاعة الذاتية بين المرضى الذين يخضعون لغسيل الكلى. الموضوعات والطريقة: التصميم: نم استخدام تصميم بحث ارتباطى وصفي. المواضيع: نفذت هذه الدراسة على 100 مر يض غسيل الكلى. المكان: أجريت الدراسة بوحدة غسيل الكلى بمستشفى السلام بمدينة بورسعيد مصر. الأدوات: تم

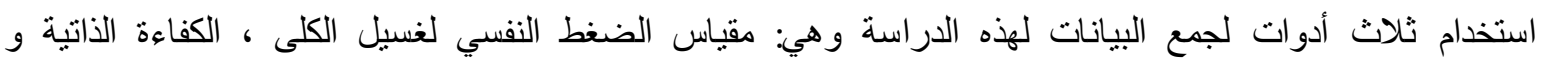
استراتيجيات التكيف لإدارة الأمراض المزمنة. النتائج: كان أبرز نسبه مئوية بين جميع الضغوط النفسية المرتبطة بعلاج غسيل الكلى المزمن مرتبطًا بالحياة الاجتماعية. كان المرضى متكيفين مع الضغوط النفسية من خلال استخدام

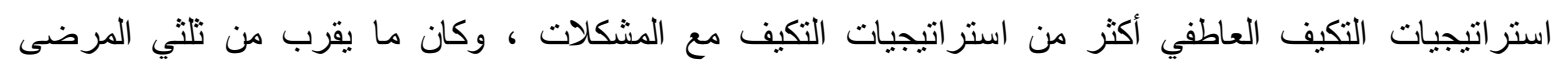
الخاضعين للدراسة لديهم مستوى منخفض من الكفاءة الذاتية. الاستنتاج والتوصيات: كان هناك ارتباطات سلبية ذات

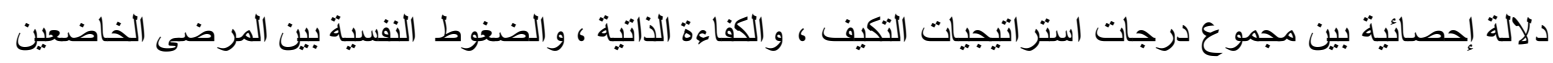
للار اسة. بينما كانت هناك علاقة ارتباط موجبة ذات دلالة إحصائية بين مجموع درجات استر اتيجيات التكيف و الكفاءة الذاتية. للتلك ، يجب أن يعقد المتخصصون الصحيون برامج تعليمية مستمرة للمرضى حول طرق التكيف المناسبة و واستر اتيجيات حل المشكلات وتقنيات إدارة الإجهاد للتخفيف من الضغوط النفسية المرتبطة بعلاج غسيل الكلى المزمن و الحفاظ على الامتثال لنظام العلاج. هذا سوف يعزز كفاءتهم الذاتية. 